\title{
To scan or not to scan, to enhance or not to enhance? That is the question
}

\author{
Lily Li *, Jonathan Costello
}

Hong Kong Med J 2014;20:464.e1

DOI: $10.12809 / \mathrm{hkmj} 134120$

A 12-year-old boy presented to the Emergency Department (ED) with reduced level of consciousness in February 2011. Collateral history established a prehospital witnessed seizure (requiring benzodiazepine administration) preceded by auditory hallucinations. Apart from uncomplicated malaria at the age of 5 years, there was no other medical history of relevance. Initial review was consistent with post-ictal presentation. An additional generalised seizure was witnessed in the ED within 30 minutes of admission requiring termination with additional intravenous benzodiazepine. In view of recurrent presentation, he was electively intubated and commenced on parenteral phenytoin. In addition, empirical acyclovir and ceftriaxone were administered. An unenhanced computed tomography
(CT) scan was normal (a). However, a subsequent enhanced scan revealed diffuse right parieto-occipital arteriovenous malformation (b). This case challenges the prevalent practice of non-performance of CT in new-onset seizure disorders and, if performed, the practice of performing solely non-enhanced CT scans in such presentations.

${ }^{1} \mathrm{~L} \mathrm{Li}$ *, MRCS (Eng), MB/BChir

2 J Costello, MRCPI, FCEM

Department of Trauma and Orthopaedics, Lister Hospital, Stevenage, Hertfordshire SG1 4AB, United Kingdom

2 Emergency Department, Royal Free Hospital, London NW3 2QG, United Kingdom

*Corresponding author: x|228@doctors.org.uk

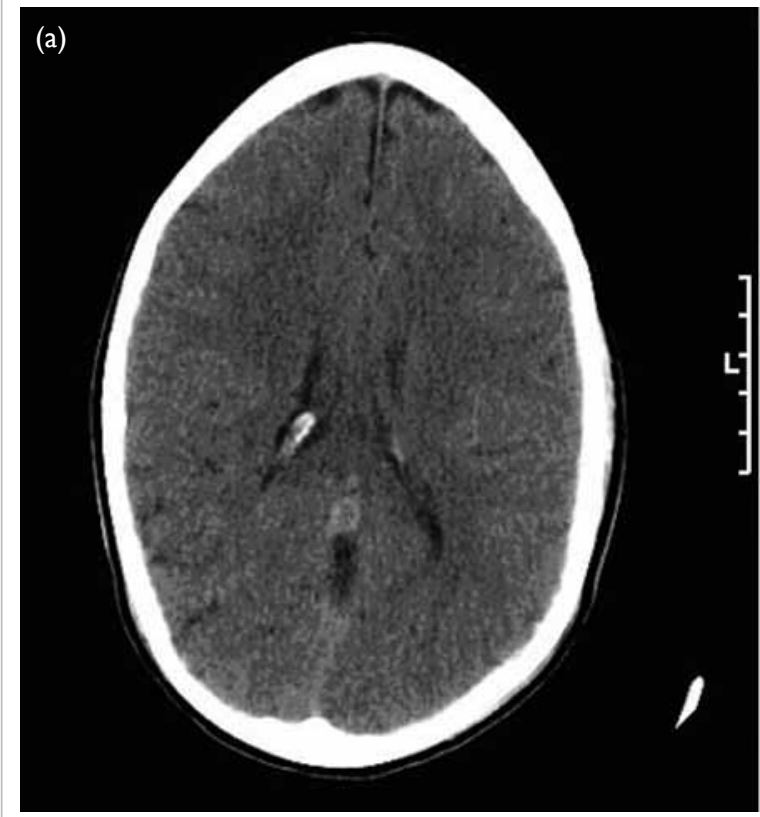

\section{(b)}

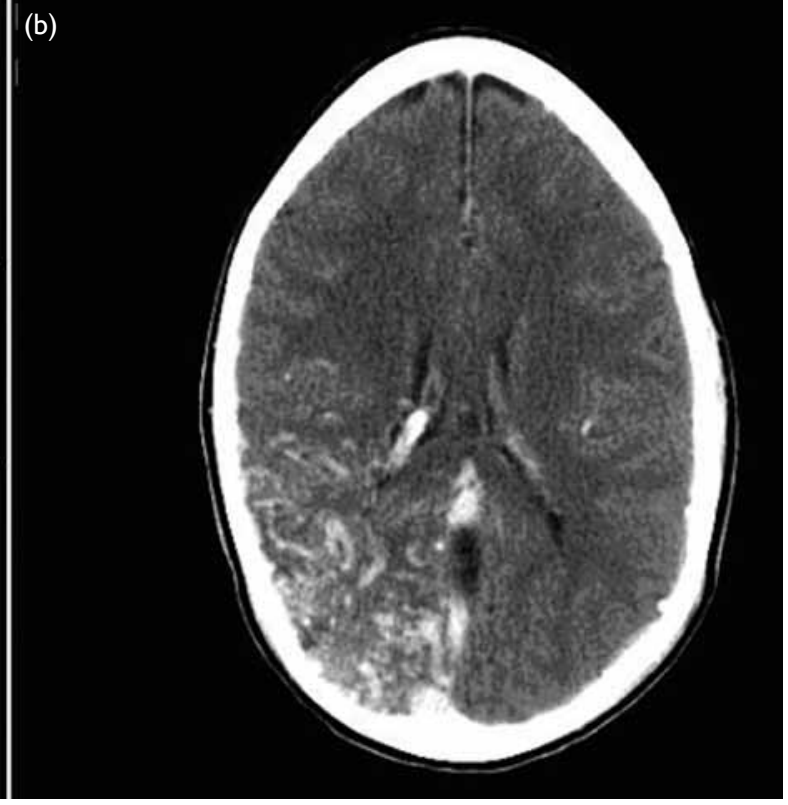

